\title{
A Wide-Bandwidth Monopolar Patch Antenna with Dual-Ring Couplers
}

\author{
Yuanyuan Zhang, ${ }^{1,2}$ Juhua Liu, ${ }^{1,2}$ Zhixi Liang, $^{1,2}$ and Yunliang Long \\ ${ }^{1}$ Department of Electronics and Communication Engineering, Sun Yat-Sen University, Guangzhou 510006, China \\ ${ }^{2}$ SYSU-CMU Shunde International Joint Research Institute, Shunde 528300, China \\ Correspondence should be addressed to Juhua Liu; liujh33@mail.sysu.edu.cn
}

Received 1 April 2014; Revised 15 June 2014; Accepted 17 June 2014; Published 29 June 2014

Academic Editor: Tat Soon Yeo

Copyright (c) 2014 Yuanyuan Zhang et al. This is an open access article distributed under the Creative Commons Attribution License, which permits unrestricted use, distribution, and reproduction in any medium, provided the original work is properly cited.

A new center-fed circular patch antenna with two coupled annular rings is presented. When the two annular rings are coupled properly, a wide band from $5.45 \mathrm{GHz}$ to $7.16 \mathrm{GHz}$ is achieved with a monopole-like radiation pattern. Measured results show that the antenna with a low profile of 0.027 wavelengths (at $5.45 \mathrm{GHz}$ ) has a bandwidth of $27.1 \%$ and a measured maximum gain of $6 \mathrm{dBi}$. The radiation pattern is omnidirectional and remains relatively stable within the operating band.

\section{Introduction}

Monopole antennas are widely used since they have an omnidirectional pattern and a vertical polarization in the horizontal plane [1]. However, the profile of a conventional monopole antenna that has a quarter wavelengths is too high for some devices or applications that desire a low-profile radiator.

Circular patch antennas (CPAs) are popular due to their advantages of low profile, low cost, and easy fabrication [2]. To realize a monopole-like radiation pattern for a CPA, various approaches have been proposed. In [3], a monopolelike radiation pattern is achieved using a CPA with a very low profile of 0.0153 wavelengths. However, the impedance bandwidth of the antenna is only $1.5 \%$. In order to improve the bandwidth, various techniques have been brought forward by researchers. In [4], the coaxial probe for the path antenna is located away from the center to improve the matching and it radiates in the broadside direction. The maximum bandwidth obtained was $3.7 \%$ with a center frequency of $5 \mathrm{GHz}$ with a relative substrate dielectric constant of 10.4 and a thickness of $1.905 \mathrm{~mm}$. By shorting a patch antenna with two wires, a patch antenna in [5] with a monopole-like radiation pattern has its size greatly minimized, but its bandwidth is only $3 \%$ for a profile of 0.06 wavelengths. The narrow bandwidths of the antennas [3-5] limit the applications in modern wireless communication systems. In recent years, to improve the bandwidth, more effective methods have been put forward. A circular patch-ring antenna [6] fabricated on PCB can generate two resonating frequencies of the same mode and provides a wide bandwidth of $12.8 \%$ with a low profile of 0.03 wavelengths. Since the patch and ring are coupled properly, its bandwidth is greatly improved. The antenna that utilizes two modes $\left(\mathrm{TM}_{01}\right.$ and $\mathrm{TM}_{02}$ modes $)$ in [7] is based on a circular patch antenna that is shorted concentrically with a set of conductive vias. The proposed antenna has a simple structure with a low profile of 0.024 wavelengths and yields a wide impedance bandwidth of $18 \%$. However, via holes must be used for the shorting points, which are not convenient for fabrication.

In this paper, we propose a center-fed circular microstrip patch antenna loaded with two annular rings to achieve a monopole-like radiation pattern and a wide bandwidth by generating three resonating frequencies. With a very low profile of $1.5 \mathrm{~mm}(0.027$ wavelengths at $5.45 \mathrm{GHz})$, the antenna has an input impedance bandwidth of $27.1 \%$ (from $5.45 \mathrm{GHz}$ to $7.16 \mathrm{GHz}$ ), a measured maximum gain of $6 \mathrm{dBi}$, and an omnidirectional radiation pattern in the horizontal plane. The antenna has a simple structure and can be easily fabricated on a thin single-layer substrate. 


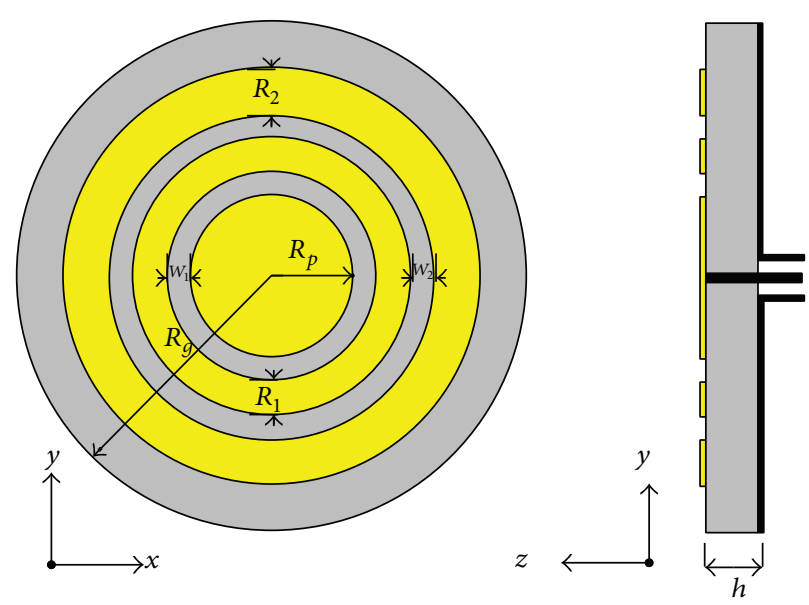

FIGURE 1: Geometry of the proposed patch antenna with dual-ring couplers.

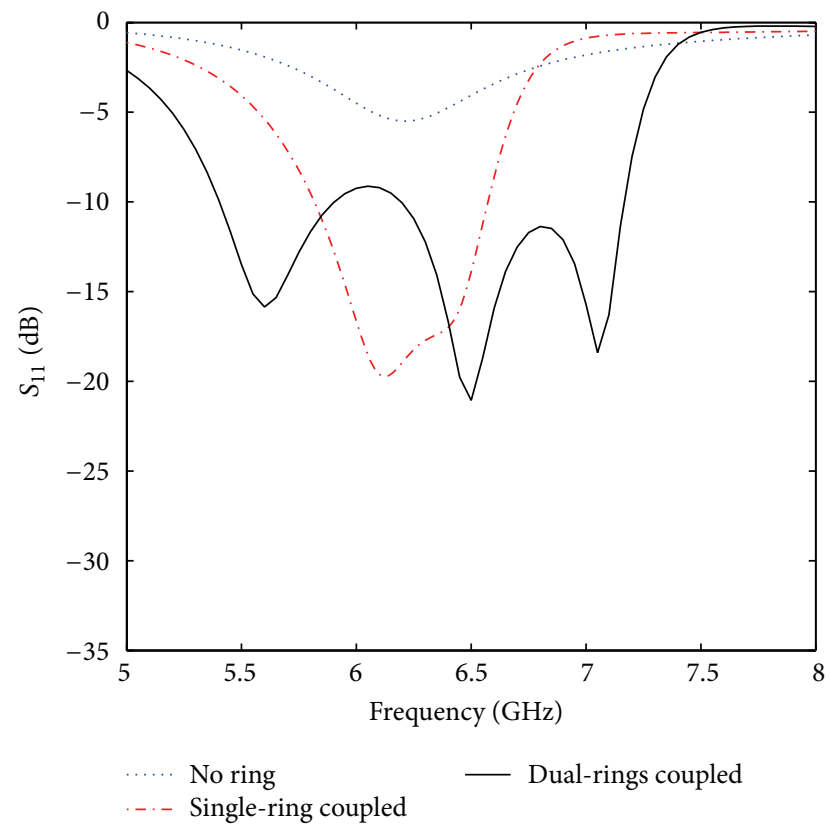

FIGURE 2: Simulated $S_{11}$ for a circular patch antenna without coupled rings, a circular patch antenna with a single-ring coupled and a circular patch antenna with a dual-ring coupled.

The proposed antenna is analyzed with a cavity model to find out the resonant mechanism. Parametric study is carried out using simulation software ANSYS HFSS [8].

\section{Antenna Design}

The geometry of the circular patch antenna loaded with two annular rings is shown in Figure 1. The antenna is fabricated on a substrate with a relative permittivity of $\varepsilon_{r}=2.55$ and a thickness of $h=1.5 \mathrm{~mm}$. The antenna is centrally fed by a coaxial connector from the back of the substrate.

On the top of the substrate, a circular patch with a radius of $R_{p}$ is placed at the center. Besides the circular patch, two
TABLE 1: The physical parameters and impedance bandwidth, for the circular patch antennas in Figure 2.

\begin{tabular}{lccc}
\hline Symbol & No ring & Single-ring coupled & dual-ring coupled \\
\hline$h$ & $1.5 \mathrm{~mm}$ & $1.5 \mathrm{~mm}$ & $1.5 \mathrm{~mm}$ \\
$\varepsilon_{r}$ & 2.55 & 2.55 & 2.55 \\
$R_{g}$ & $60 \mathrm{~mm}$ & $60 \mathrm{~mm}$ & $60 \mathrm{~mm}$ \\
$R_{p}$ & $18 \mathrm{~mm}$ & $18 \mathrm{~mm}$ & $18 \mathrm{~mm}$ \\
$R_{1}$ & & $12 \mathrm{~mm}$ & $12.25 \mathrm{~mm}$ \\
$W_{1}$ & & $1 \mathrm{~mm}$ & $0.3 \mathrm{~mm}$ \\
$R_{2}$ & & & $11.25 \mathrm{~mm}$ \\
$W_{2}$ & & & $13 \%$ \\
$B W$ & & $13 \%$ & $27 \%$ \\
\hline
\end{tabular}

rings with widths of $R_{1}$ and $R_{2}$ are concentrically loaded. The width of the slot between the circular patch and the inner ring is $W_{1}$ and the width of the slot between the inner ring and outer ring is $W_{2}$. The ground plane radius $R_{g}$ is $60 \mathrm{~mm}$.

The design procedure of the antenna is similar to that of a conventional patch antenna with two or three parasitic patches. Firstly, the circular patch is designed for the center frequency of $5.8 \mathrm{GHz}$ (without the annular rings coupled). Using the cavity model [9], the radius of the circular patch $R_{p}$ can be calculated and set as $18 \mathrm{~mm}$. Secondly, the size of inner ring can be roughly predicted for a resonant frequency slightly higher than $5.8 \mathrm{GHz}$, from the equation for annular ring microstrip antenna [10]. Thirdly, the radius width $R_{2}$ of the outer ring can be calculated in the same way with a resonant frequency close to that of the inner ring. So, the values of $R_{1}$ and $R_{2}$ are set as $12 \mathrm{~mm}$ and $11 \mathrm{~mm}$, approximately. Finally, the widths of slots $\left(W_{1}\right.$ and $\left.W_{2}\right)$ and the widths of the rings $\left(R_{1}\right.$ and $\left.R_{2}\right)$ are optimized to obtain a wide bandwidth, using HFSS simulation. The values of the optimized parameters are given in Table 1.

The proposed antenna achieves a wider bandwidth compared to conventional circular microstrip patch or circular microstrip patch with a single ring. The impedance bandwidth and physical parameters of the three antennas are 


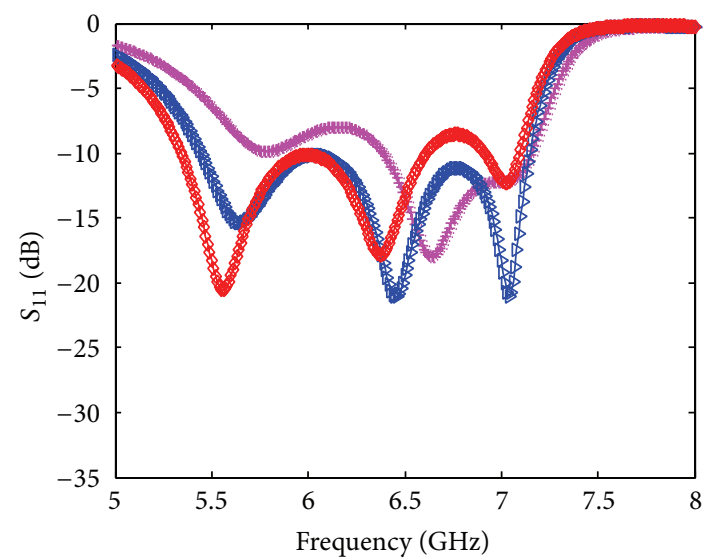

$\rightarrow R_{p}=17 \mathrm{~mm} \rightarrow R_{p}=18.5 \mathrm{~mm}$
$\rightarrow R_{p}=18 \mathrm{~mm}$

(a)

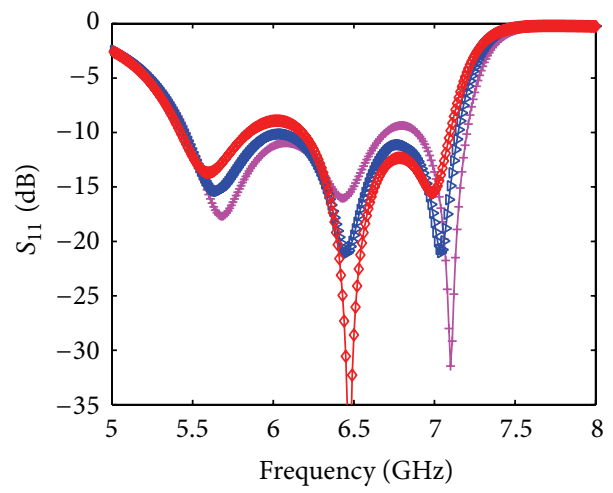

$\begin{aligned} & \rightarrow W_{2}=0.8 \mathrm{~mm} \\ & \rightarrow W_{2}=1 \mathrm{~mm}\end{aligned} \rightarrow W_{2}=1.2 \mathrm{~mm}$

(c)

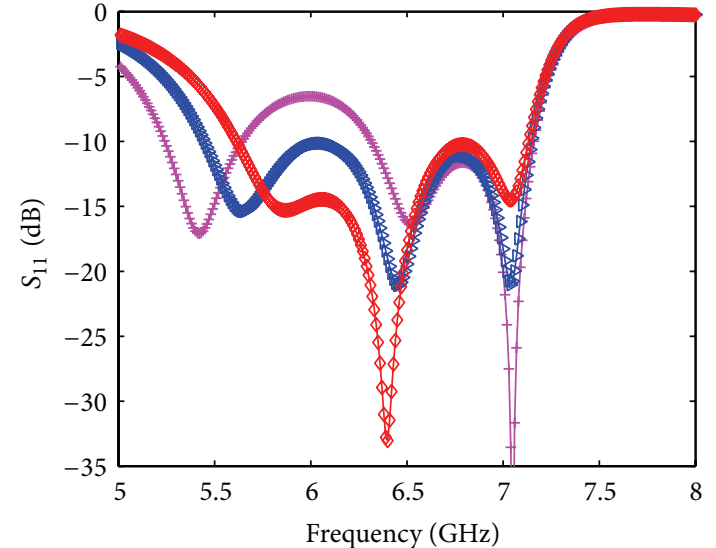

$\rightarrow W_{1}=0.2 \mathrm{~mm} \quad \rightarrow W_{1}=0.4 \mathrm{~mm}$

(b)

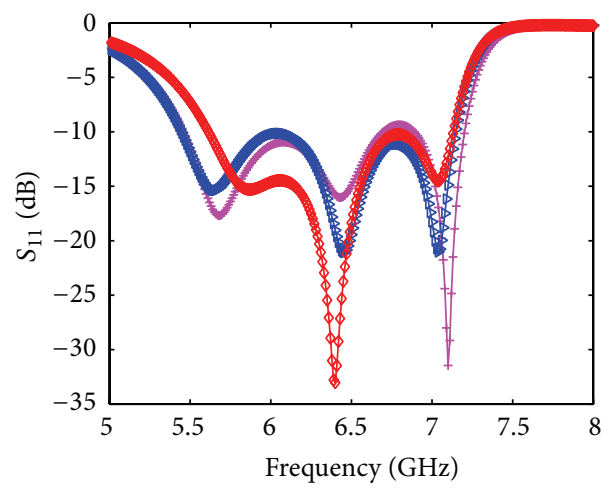

$\longrightarrow R_{1}=12 \mathrm{~mm}$

$\rightarrow R_{1}=12.25 \mathrm{~mm}$

(d)

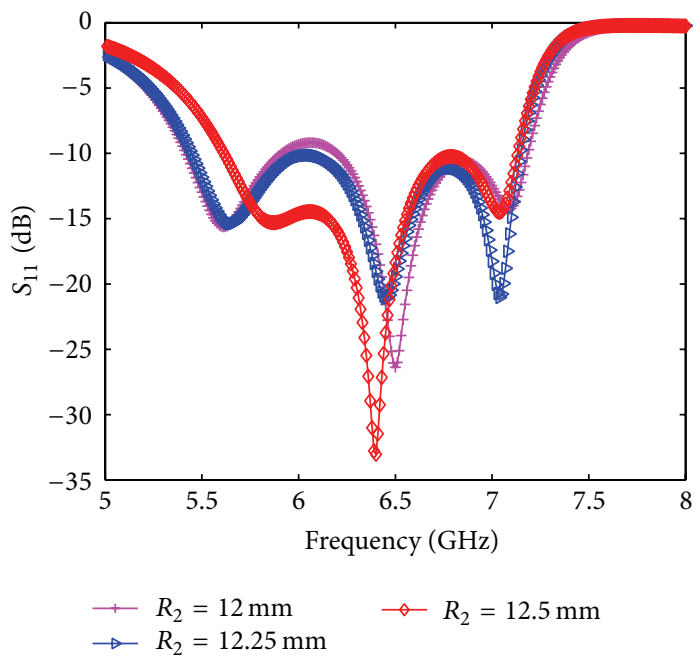

(e)

FIGURE 3: Simulated $S_{11}$ for the proposed antennas with different parameters. (a) Simulated $S_{11}$ for different $R_{p}\left(W_{1}=0.3 \mathrm{~mm}, W_{2}=1 \mathrm{~mm}, R_{1}\right.$ $\left.=12.25 \mathrm{~mm}, R_{2}=11.25 \mathrm{~mm}\right)$. (b) Simulated $S_{11}$ for different $W_{1}\left(R_{p}=18 \mathrm{~mm}, W_{2}=1 \mathrm{~mm}, R_{1}=12.25 \mathrm{~mm}, R_{2}=11.25 \mathrm{~mm}\right)$. (c) Simulated $S_{11}$ for different $W_{2}\left(R_{p}=18 \mathrm{~mm}, W_{1}=0.3 \mathrm{~mm}, R_{1}=12.25 \mathrm{~mm}, R_{2}=11.25 \mathrm{~mm}\right)$. (d) Simulated $S_{11}$ for different $R_{1}\left(R_{p}=18 \mathrm{~mm}, W_{1}=0.3 \mathrm{~mm}\right.$, $\left.W_{2}=1 \mathrm{~mm}, R_{2}=11.25 \mathrm{~mm}\right)$. (e) Simulated $S_{11}$ for different $R_{2}\left(R_{p}=18 \mathrm{~mm}, W_{1}=0.3 \mathrm{~mm}, W_{2}=1 \mathrm{~mm}, R_{1}=12.25 \mathrm{~mm}\right)$. 


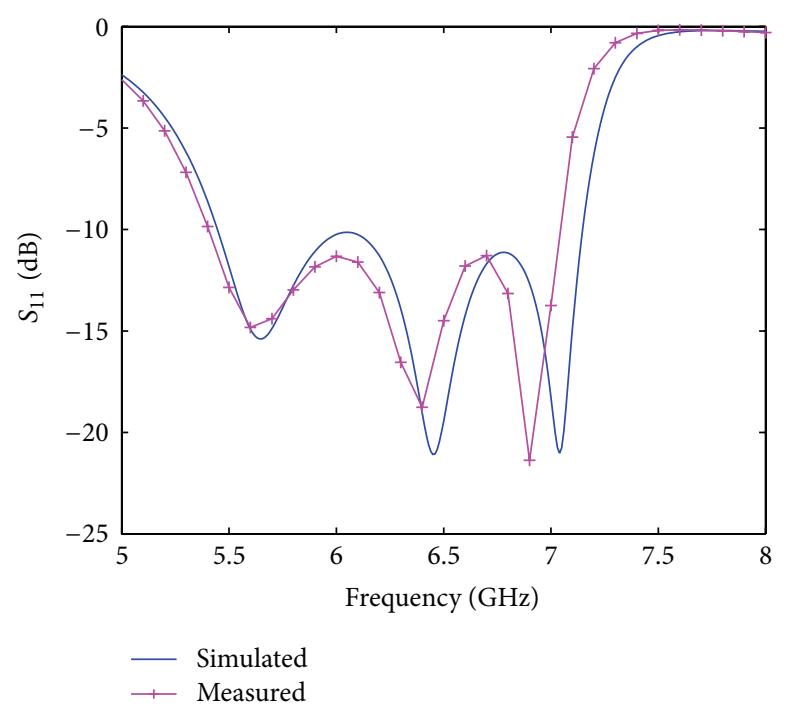

FIGURE 4: Simulated and measured $S_{11}$ for the proposed antenna.

presented in Table 1. As shown in solid line in Figure 2, the simulated reflection coefficient for the proposed antenna is less than $-10 \mathrm{~dB}$ in the band from $5.45 \mathrm{GHz}$ to $7.16 \mathrm{GHz}$, with a fractional bandwidth of $27.1 \%$. The $-10 \mathrm{~dB}$ returnloss band of the single-ring circular patch antenna is from 5.76 to $6.59 \mathrm{GHz}$, with a fractional bandwidth of $13 \%$. The antenna with a single-ring coupled and the proposed antenna produce a similar monopole-like radiation pattern with a gain of about $5.7 \mathrm{dBi}$ and $6 \mathrm{dBi}$, respectively. The bandwidth of the presented antenna is over $51 \%$ wider than that of the circular patch antenna with a single annular ring coupled. The bandwidth could be further improved with more coupled rings but with a higher complexity in the design. And we will study in the further study.

\section{Parametric Study}

From the previous section, it is noticed that several parameters have influences on the resonant frequencies and the matching of the antenna. In this section, we will demonstrate the effect of each of these parameters.

As shown in Figures 3(a), 3(d), and 3(e), $f_{1}$ increases with the decrease of $R_{p}, f_{2}$ increases with the decrease of $R_{1}$, and $f_{3}$ increases with the decrease of $R_{2}$. Then, it is observed that these simulation results above agree with the cavity theory.

In Figures 3(b) and 3(c), the gap between the centre patch and the first annular ring must be very small to have a wide bandwidth, because the coupling must be strong enough to make the coupled rings work [11]. In the design of the antenna, the gap between the first and the second annular rings also needs to be tuned to control the coupling strength between them.

\section{Experiment Result}

With the help of simulation, the dimensions of the proposed antenna are optimized to be $R_{p}=18 \mathrm{~mm}, R_{1}=12.25 \mathrm{~mm}$,
$R_{2}=11.25 \mathrm{~mm}, W_{1}=0.3 \mathrm{~mm}$, and $W_{2}=1 \mathrm{~mm}$. A prototype is fabricated and measured. Good agreement between the measured and simulated results is observed in Figure 4. With the definition of $-10 \mathrm{~dB}$ reflection coefficients, the measured input impedance bandwidth is $1.61 \mathrm{GHz}$ (from 5.45 to $7.16 \mathrm{GHz}$ ), which is about $27.1 \%$ input impedance bandwidth.

The radiation patterns for the proposed antenna are simulated and measured at the three resonant frequencies within the bandwidth. The measured radiation patterns agree well with the HFSS simulations, and a monopole-like pattern is obtained. Figures 5(a), 5(c), and 5(e) show the simulated and measured E-plane radiation patterns at 5.64, 6.4, and $7.04 \mathrm{GHz}$, respectively. The cross polarization is about $20 \mathrm{~dB}$ below the copolarization level. The $\mathrm{H}$-plane patterns are shown in Figures 5(b), 5(d), and 5(f). The pattern is omnidirectional and the cross polarization level is more than $15 \mathrm{~dB}$ below that of the copolarization level. The maximum gain and the gain in omnidirection for the proposed antenna are shown in Figures 6(a) and 6(b), respectively. Measured result shows that the proposed antenna obtains a maximum gain of about $6 \mathrm{dBi}$, which agrees well with the HFSS simulations.

\section{Conclusion}

A new center-fed circular patch antenna with dual-ring couplers is presented. Triple-resonance behavior is observed in the antenna, which contributes a wide bandwidth for the antenna with a very low profile of only 0.027 wavelengths (at $5.45 \mathrm{GHz}$ ). Measured result shows that the antenna has a bandwidth of $27.1 \%$ and produces a monopole-like radiation pattern with a gain of about $6 \mathrm{dBi}$. The bandwidth of the proposed antenna is over $51 \%$ wider than the bandwidth of the antenna with single-ring coupled. This antenna has a good potential for wireless communications. 


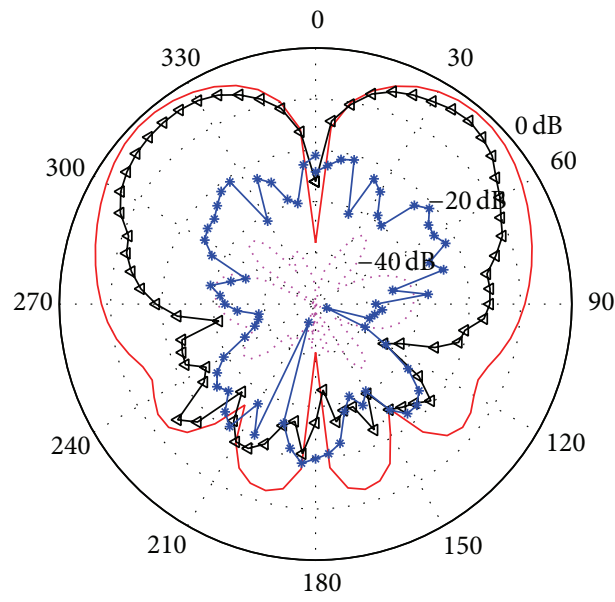

(a)

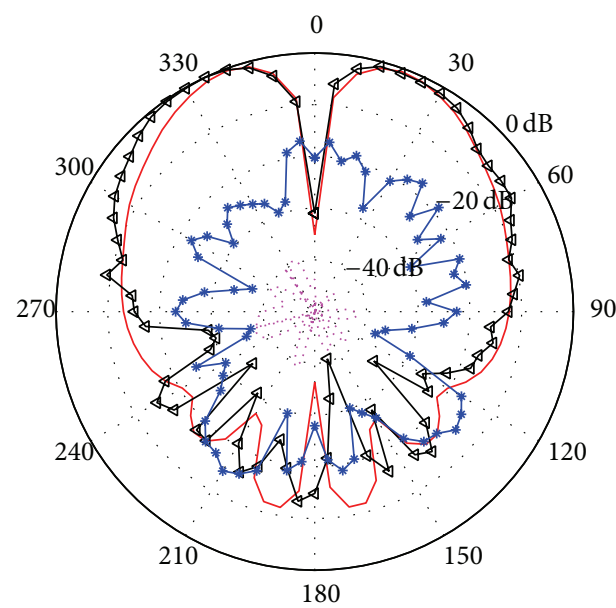

(c)

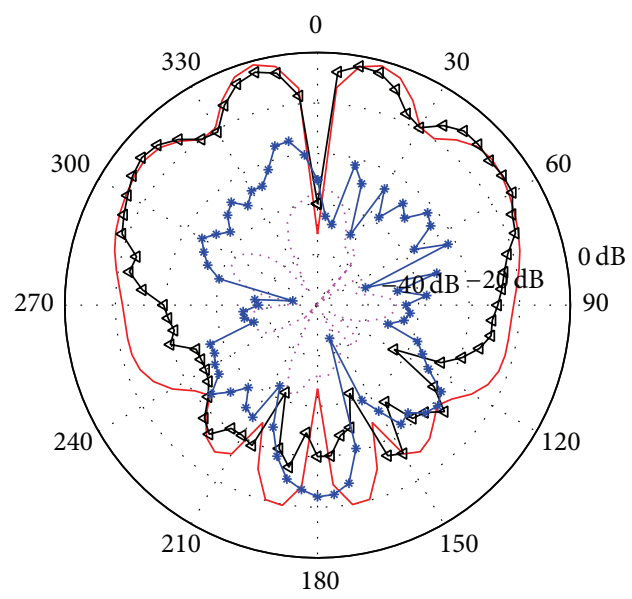

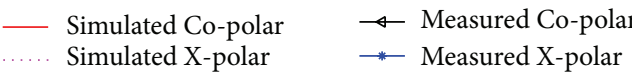

(e)

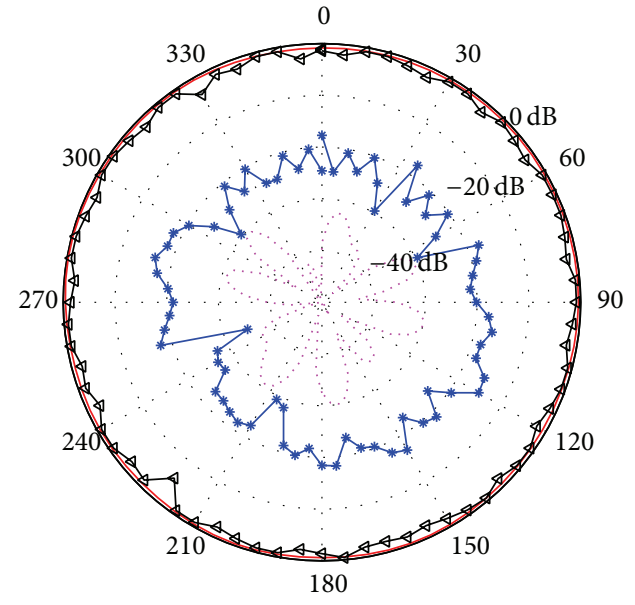

(b)

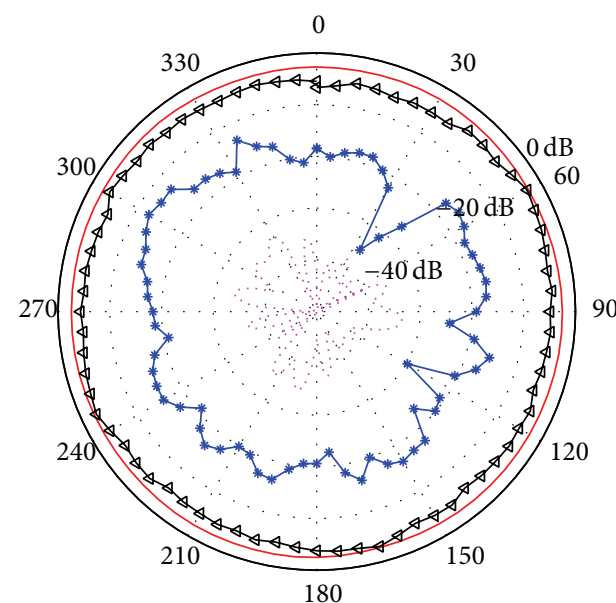

(d)

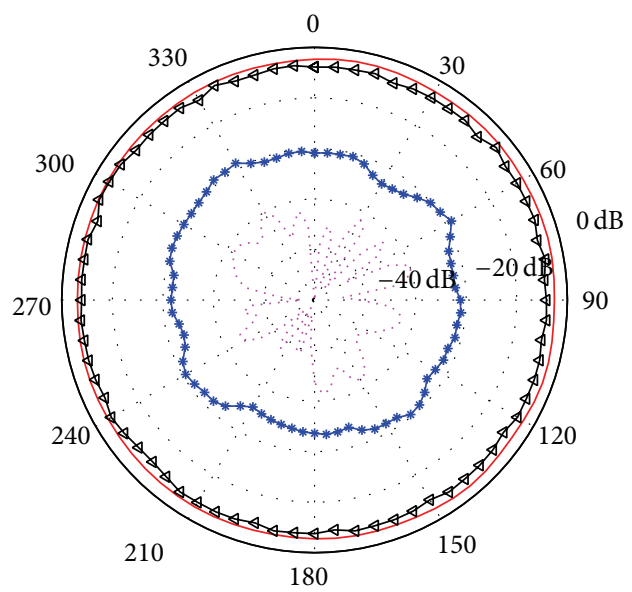

$\dashv$ Measured Co-polar

$\rightarrow$ Measured X-polar

(f)

Figure 5: E-plane radiation patterns for the proposed antenna at (a) $5.64 \mathrm{GHz}$; (c) $6.4 \mathrm{GHz}$; and (e) $7.04 \mathrm{GHz}$. $H$-plane radiation patterns for the proposed antenna at (b) $5.64 \mathrm{GHz}$; (d) $6.4 \mathrm{GHz}$; and (f) $7.04 \mathrm{GHz}$. 


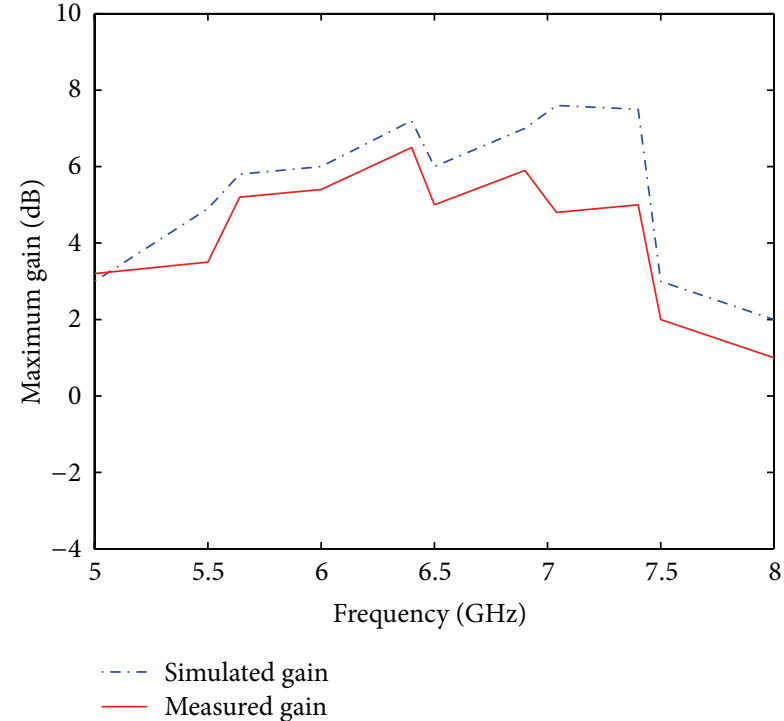

(a)

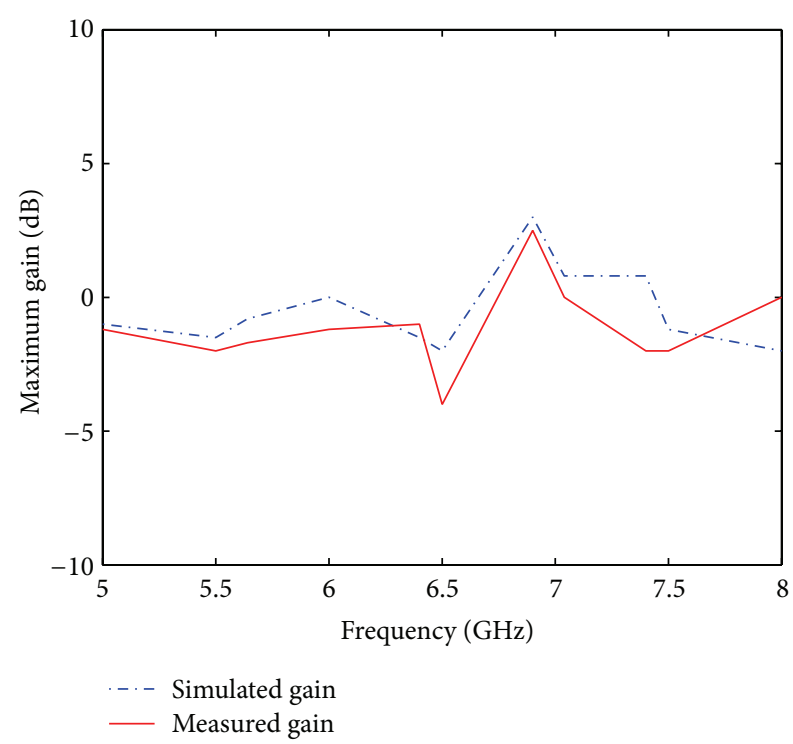

(b)

Figure 6: (a) Maximum gain for the proposed antenna. (b) Gain in omnidirection for the proposed antenna.

\section{Conflict of Interests}

The authors declare that there is no conflict of interests regarding the publication of this paper.

\section{Acknowledgment}

This work was supported in part by the Research Project of Guangdong Province (2012B091100050).

\section{References}

[1] W. L. Stutzman and G. A. Thiele, Antenna Theory and Design, Wiley, New York, NY, USA, 2nd edition, 1998.

[2] J. R. James and P. S. Hall, Handbook of Microstrip Antennas, vol. 28 of IEE Electromagnetic Wave Series, chapter 1, The Institution of Engineering and Technology, London, UK, 1989.

[3] L. Economou and R. J. Langley, "Patch antenna equivalent to simple monopole," Electronics Letters, vol. 33, no. 9, pp. 727-729, 1997.

[4] D. M. Kokotoff, R. B. Waterhouse, C. R. Birtcher, and J. T. Aberle, "Annular ring coupled circular patch with enhanced performance," Electronics Letters, vol. 33, no. 24, pp. 2000-2001, 1997.

[5] C. Delaveaud, P. Leveque, and B. Jecko, "New kind of microstrip antenna: the monopolar wire-patch antenna," Electronics Letters, vol. 30, no. 1, pp. 1-2, 1994.

[6] A. Al-Zoubi, F. Yang, and A. Kishk, "A broadband center-fed circular patch-ring antenna with a monopole like radiation pattern," IEEE Transactions on Antennas and Propagation, vol. 57, no. 3, pp. 789-792, 2009.

[7] J. Liu, Q. Xue, H. Wong, H. W. Lai, and Y. Long, "Design and analysis of a low-profile and broadband microstrip monopolar patch antenna," IEEE Transactions on Antennas and Propagation, vol. 61, no. 24, pp. 11-18, 2013.
[8] HFSS: High Frequency Structure Simulator Based on Finite Element Method, v.10.0, Ansoft, 2005.

[9] R. Garg, P. Bhartia, I. Bahl, and A. Ittipiboon, Microstrip Antenna Design Handbook, chapter 4, Artech House, Norwood, Mass, USA, 2001.

[10] J. R. James and P. S. Hall, Handbook of Microstrip Antennas, vol. 28 of IEE Electromagnetic Wave Series, Chapter 5, London, UK, 1989.

[11] T. Chakravarty, S. Biswas, A. Majumdar, and A. De, "Computation of resonant frequency of annular-ring-loaded circular patch using cavity model analysis," Microwave and Optical Technology Letters, vol. 48, no. 3, pp. 622-626, 2006. 

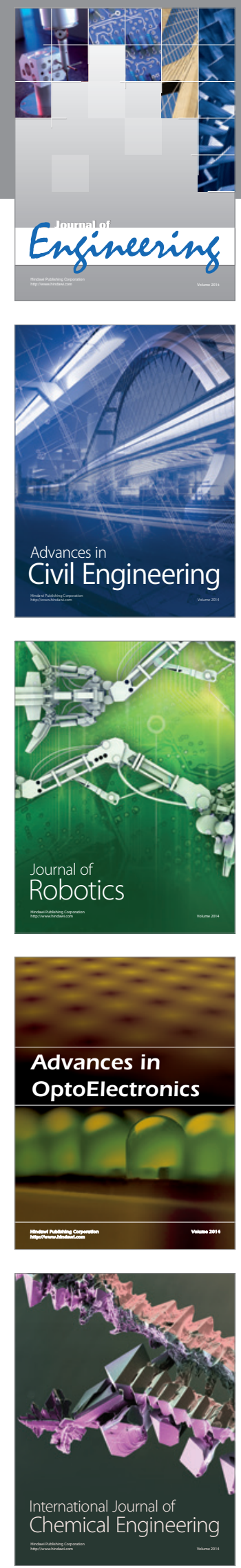

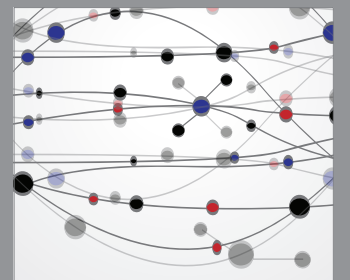

The Scientific World Journal
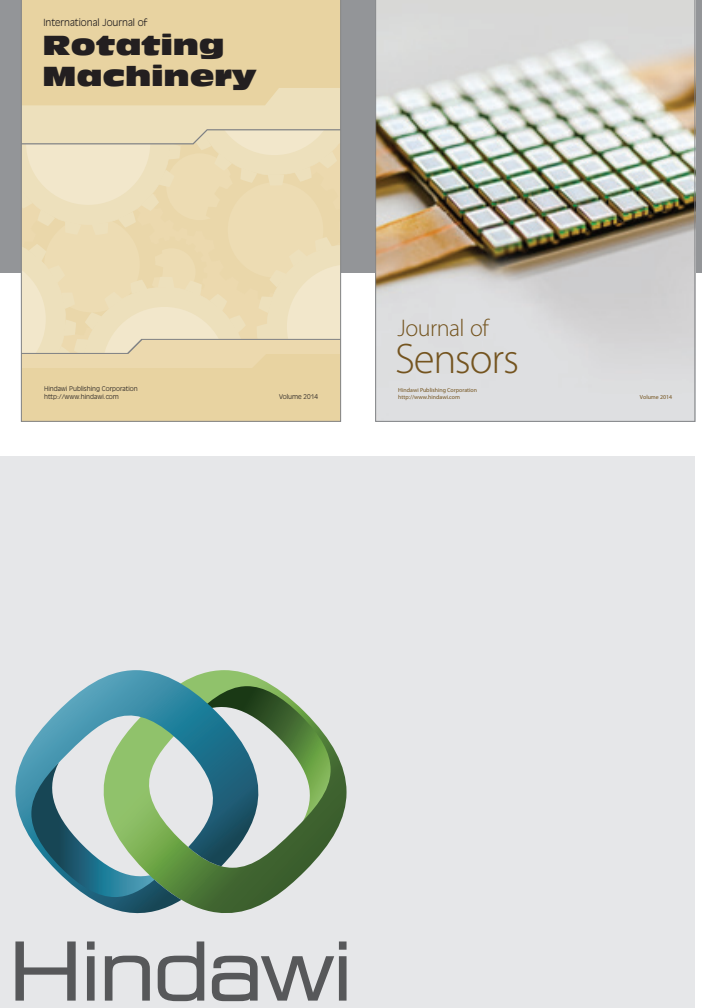

Submit your manuscripts at http://www.hindawi.com
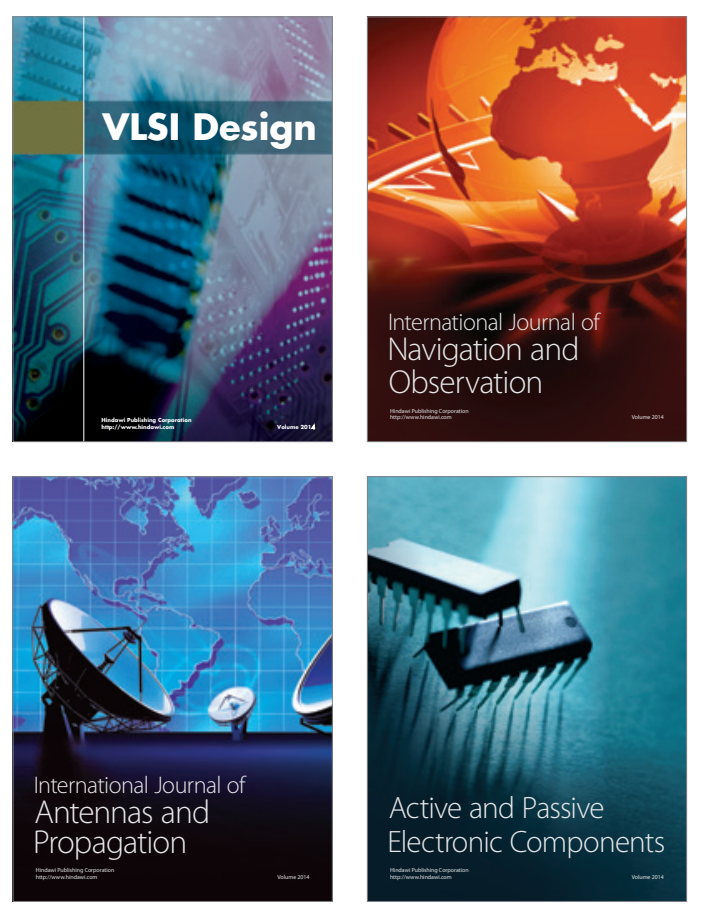
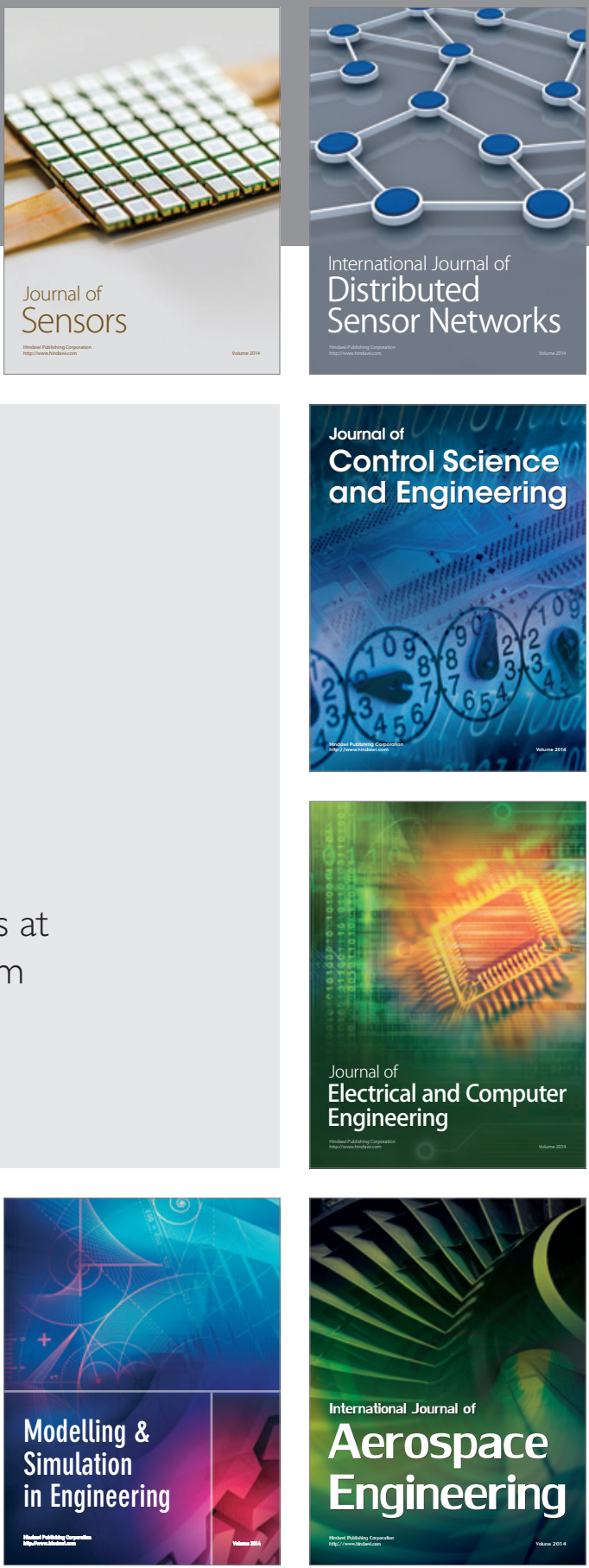

Journal of

Control Science

and Engineering
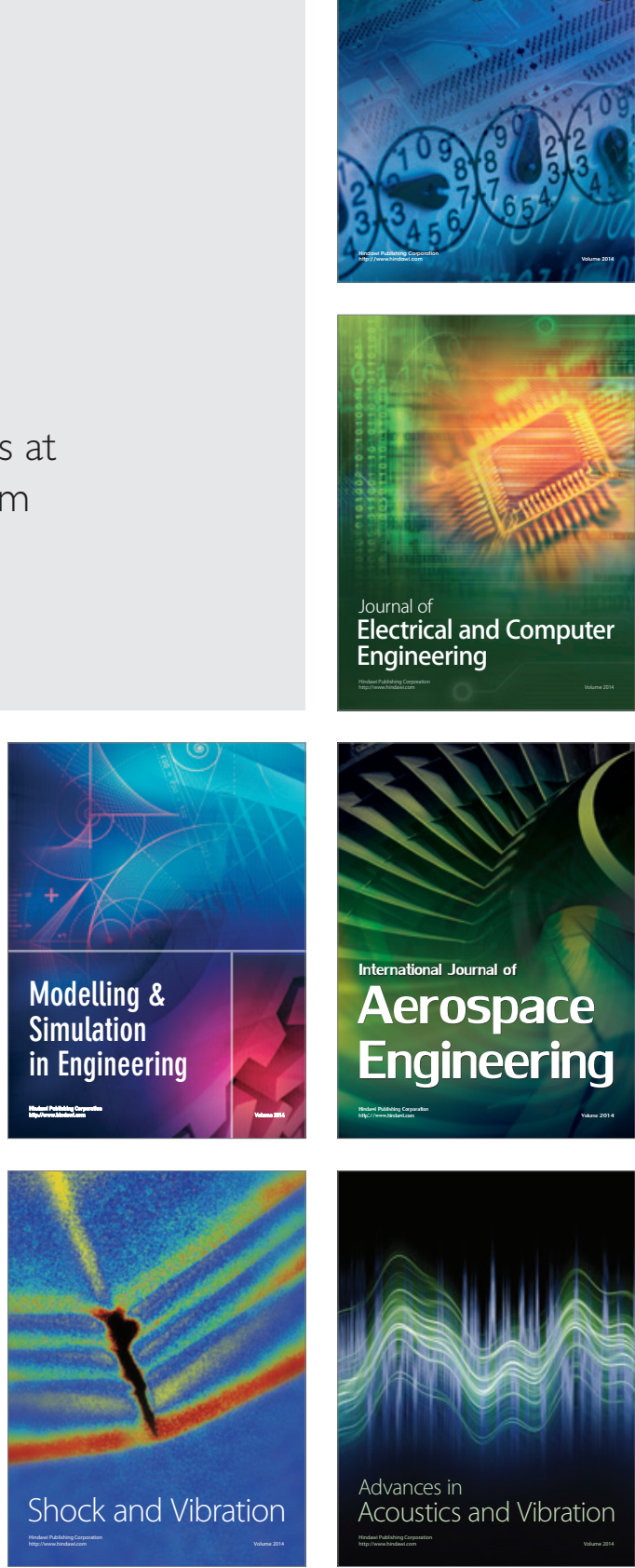